\title{
CÍCERO, O SENADO E O FIM DA REPÚBLICA ROMANA.
}

\author{
DANIEL VALLE RIBEIRO \\ Da Faculdade de Filosofia e Ciênclas Humanas da \\ Universidade Federal de Minas Gerais:
}

Para o estudante universitário de História, futuro professor ou pesquisador da disciplina, o estudo de Roma assume indiscutível relêvo no programa da Cadeira de História da Antiguiidade. Dos mais fascinantes, porém complexo e difícil, é o período das Guerras Civis, cujo epílogo se identifica com a última fase da República e o advento do Império.

Deparamos, de início, com a precariedade de nossas fontes, tendo em vista o desaparecimento de memórias, panfletos, debates na Assembléia e no Senado, ou discursos ali proferidos. Contamos com úteis fragmentos da História Romana de Apiano, concernentes às Guerras Civis, mas de composição posterior. Dispomos, em troca, de César, de Salústio, da correspondência e dos discursos de Cícero. Entretanto, como lembra Harmand, não possuímos nada semelhantes às Comédias de Aristófanes, preciosas para reconstituir o estado de opinião dominante na época (1). Assim, por exemplo, pouco podemos esclarecer acêrca do que pensava a massa a respeito de César, de Pompeu ou de Cícero. Conhecemos tão-sòmente a atitude dêsses chefes, graças aos historiadores antigos. Ȧ vista disso, o tema que nos propusemos tratar, encerra no seu contexto dificuldades sem conta ao historiador moderno.

Não devemos considerar senão como um todo êsse período de meio século de que as ininterruptas guerras civis constituem a textura e cujo têrmo será determinado pela vitória definitiva de Otávio. O destino das instituições republicanas reflitirá, indubitàvelmente, o condicionamento histórico ditado pela expansão. Com efeito, a conquista criaria para a República graves dificuldades com a transformação da antiga Cidade-Estado em verdadeiro estado mundial. A

(1). - Cf. o interessante artigo de HARMAND, Louis. "Les guerres civiles et la fin de la république romaine". L'Information Historique. Paris, 2: 47-53, J.-B. Balllière et Fils, Mars-Avril 1966. 
anexação de Cartago e dos mais importantes centros comerciais do Oriente acarretou-lhe sério desequilíbrio: Roma perdeu seu caráter agrícola e pastoril para tornar-se uma polis devotada à especulação financeira. O imperialismo crescente converteu Roma em um estado dominador, que, nas ocasiões necessárias, retirava o camponês de suas terras para transformá-lo em soldado, com prejuízo evidente para sua organização interna.

A atração incoercível exercida pelo Eldorado Oriental impeliu Roma para a política de colonialismo, que tão severos efeitos the acarretaria à ordem interna: dissolução dos costumes, enfraquecimento do patriotismo e o afrouxamento dos laços de família e da religião. Se a conquista representava o desenvolvimento do sistema capitalista e favorecia transformações na técnica agrícola, introduziu profunda revolução nos hábitos e na economia de vida, nas regras gerais de conduta com a extensão gradual da dominação romana até os países de cultura grega e, em seguida, até o Oriente.

\footnotetext{
"Todos os refinamentos da vida escreveu Ciccotti - desconhecidos ou quase desconhecidos aos romanos, se lhes oferecem então como atrativo, sedução de uma coisa nova, difícil de resistir" (2).
}

O afluxo de dinheiro, decorrente da exploração das províncias, estimulou inúmeros empreendimentos comerciais, animou a prática da usura e taxas elevadas nos negócios imobiliários e na provisão dos exércitos. Por outro lado, a retirada do homem do campo para atender à conquista, exigia o emprêgo do escravo na atividade agrícola .

Alterações tão substanciais abalavam o Estado Romano, mas a aristocracia senatorial, ciosa de sua fôrça, e não desejando perder sua posição, transformava-se em oligarquia tirânica (3). Dessa forma, a antiga Constituição romana, descrita por Políbio como um sistema perfeito, que reunia os três grandes tipos de constituição - monárquica, aristocrática e democrática -, mostrava-se incapaz de atender às necessidades cada vez maiores de um império mediterrâneo. O Senado, por seu turno, se revelaria inepto para uma reforma que atendesse aos interêsses do estado e amenizasse a luta vigorosa entre a aristocracia e a Ordem eqüestre.

Um fator nôvo, de importância preponderante nos acontecimentos futuros, surgiria agora: o exército profissional, originado da reforma de Mário, que levaria fatalmente

\footnotetext{
(2). - CICCOTTI, Le Déclin de L'Esclavage Antique. Atrad. franc.). Paris, 1910. p. 232, In "Eremildo $\mathrm{L}$. Vianna. Uma fase do imperialismo romano: A Guerra de Roma contra Jugurta". Rio, 1945. p. 43-4.

(3). - VIANNA (Eremildo L.), Op. cit. p. 44.
} 
"aux pronunciamientos et à la dictature militaires" (4).

O nôvo exército atraiu o proletariado com a perspectiva de vantagens resultantes dos saques e a promessa de recompensa de terras no final do período de serviço militar. Tornou-se uma arma poderosa, porém ameaçadora, já que os soldados se consideravam "homens do seu general", o que deixava desamparada as instituições, à mercê dos ambiciosos.

A principal missão dos futuros dirigentes resumia-se, portanto, em reformar a Constituição, adaptando-a às novas contingências, possibilitando governar não sòmente a Itália, mas todos os territórios que, agora, compreendiam o vasto império romano. Lúcio Cornélio Sila foi o primeiro a perceber a nova feição da luta e o primeiro a empregar em seu próprio proveito o nôvo fator surgido na vida política de Roma. De sua vitória na guerra civil, extraiu um imperium excepcional, impondo-se como ditador, sem investidura consular, por tempo indeterminado. O regime inaugurado por Sila, sancionado pela lex Valeria, resultava da ruína irreparável do sistema oligárquico e marcava o advento da era do poder pessoal, que levaria à monarquia militar. Embora manquée, segundo a celebrada fórmula (5), sua tentativa monárquica conheceria vitorioso curso e acabaria por impor-se cinqüenta anos mais tarde.

Dessa maneira, Roma chegava ao século I a. C. suportando autêntica revolução na vida republicana e acabaria por consagrar as antigas tentativas de implantação de um regime baseado no poder pessoal. A mística do herói providencial, destinado a ocupar no estado o primeiro lugar, flui como esperança e se firmará como doutrina de salvação pública.

\footnotetext{
"Esses homens eminentes - assinala Harmand -, que pairam sôbre seus contemporâneos por suas qualidades, suas iniciativas ousadas, seu prestígio, passam aos olhos daqueles que os admiram ou os temem como sêres providenciais" (6).
}

Esse "romantismo da glória" conduzirá, certamente, a uma política de fôrça, estranha à tendência das instituições: Bom ou mau grado, a idéia monárquica triunfou sem contar com a aversão dos primeiros tempos, instalando-se sem Golpe de Estado ou recurso à ditadura, mas pela absorção de todos os poderes nas mãos de um

\footnotetext{
(4). - BLOCH (Gustave) e CARCOPINO (Jérôme), Des Gracques a Sulla. In "La République Romaine de 133 avant J. C. a la Mort de César". 3 ed., Paris, PUF, 1952 (Histoire Romaine, t. II). p. 327.

(5). - CARCopiNo (Jérôme), sylla ou la monarchie manquée. Paris, L'Artisan du Livre, 1947.

(6). - HARMAND, Op. cit., 44.
} 
magistrado, que elevou sua autoridade acima das instituições. Delineara-se já o terreno e o Principado não seria senão o desfêcho de um velho estado de coisas, epílogo natural do drama em que se debatia a nobilitas desde a centúria precedente e a solução do status gerado com o expansionismo.

Ainda durante o seu predomínio, cujo esplendor alcançou o início do século II, conheceu a aristocracia senatorial violentos ataques da outra classe dirigente. No entanto, viu-se obrigada a fazer concessões aos cavaleiros, enriquecidos com as guerras e com a exploração das províncias. A rivalidade entre a nobreza e os equites conduziu a uma política de envilecimento e ao esmagamento do pequeno proprietário, êste um dos fatôres essenciais ao equilíbrio institucional da República.

O desaparecimento do pequeno camponês, observa judiciosamente Homo, acabou privando os comitia tributa de seu elemento ponderador, em breve substituído por eleitores profissionais (7). A alteração da Assembléia das Tribos correspondeu às modificações das próprias tradições políticas, libertando os magistrados da autoridade do Senado e culminando, no decorrer do século I, com a entrega do comando militar a ambiciosos do tipo de Pompeu e de César.

As conquistas, vale repetir, paralelamente à grandeza e ao aprimoramento da técnica agrícola, determinaram alterações substanciais à fisionomia do estado, submetendo a própria aristocracia senatorial aos efeitos das transformações econômicas, usurpando-lhe ainda, com a reforma de Mário, o poder militar. Dispor de um exército para dominar a República tornou-se o alvo de todos os que ambicionavam um lugar ao sol. Erguendo-se em supremo guardião das instituições, o Senado sempre reagiu, defendendo-se de todos os assaltos de partido popular, ou adotando medidas corajosas diante do prestígio crescente dos generais. Todavia, qualquer iniciativa, prudente ou arrojada, esbarrava sempre na submissão da vida política ao exército permanente, já que o tradicional regime aristocrático, baseado em um exército de camponeses, degenerou em uma poderosa oligarquia de famílias opulentas desprovidas de fôrça militar .

Malgrado a pronunciada debilidade das velhas famílias patrícias, a classe dos optimates repelia o homo novus. Entretanto, cabe salientar; o temido crescimento da burguesia poderia significar a renovação da nobilitas. Diante de tantas dificuldades, procurou a nobreza, ainda no século II, fortalecer sua hegemonia sôbre o Senado e magistraturas. Contudo, não pôde,

(7). - HOMO (León), Les Institutions Politiques Romaines. Coll. "L'Evolution de L'Humanité", dir. Henrt Berr. Paris, Ed. Albin Michel, 1950. v. XVIII. p. 184 . 


\begin{abstract}
"em época essêncialmente de conquistas, evitar que magistrados providos de comandos tivessem a iniciativa própria de govêrno ou usassem de poderes ilimitados nas províncias",
\end{abstract}

afirma Eremildo Vianna (8). Por seu turno, como conseguiria o Senado fazer-se cidadela de uma aristocracia corrompida e quase inútil, desarmada também das fôrças do espírito?

Temos, pois, que o declínio da Constituição tradicional, de que era sintomático a disfunção do sistema oligárquico, decorria de duas causas fundamentais: a divergência e conseqüente dicotomia da nobreza nas classes senatorial e equiestre; e o desaparecimento da classe média, acima referido. A solução $\mathrm{d}_{\mathrm{o}}$ problema residia, portanto, na recomposição do equilíbrio. Em outros têrmos: na restauração do grupo dirigente e na reconstituição da classe média. A segunda parte da questão implicava dois aspectos de suma gravidade, ligando-se não apenas à esfera da política externa, já que, desfalcando as legiões do melhor de seus efetivos, pelo esgotamento das fontes de recrutamento, expunha ao perigo a própria sobrevivência das instituições. Tentativas de reforma foram experimentadas pelos Gracos, através da solução agrária, e por Lívio Druso, que cuidou também da questão italiana, únicos instrumentos eficazes para promoverem o revigoramento da Constituição, restabelecendo o equilíbrio de outrora e, conseqüentemente, permitindo o adequiado funcionamento da vida republicana.

Entretanto - repetindo a lúcida observação de Rostovtzeff - o antigo Estado Romano de camponeses estava definitivamente sepultado e qualquer iniciativa que visasse à criação de núcleos agrícolas para os proletários era contida pela oligarquia (9). O caminho parecia, dessa forma, livre à idéia do poder pessoal, e Roma, embora tendesse à democracia, passaria da oligarquia à tirania, que lhe abriria as portas à monarquia militar. E como previra Sila, a monarquia surgia como a forma apropriada às novas condições da antiga polis e Roma, impelida por suas conquistas, não podia resistir-lhe à intrusão.

Verifica-se, assim, a absoluta incapacidade da velha Constituição de socorrer o agonizante regime republicano e a falta de espírito público dos homens da aristocracia senatorial agravava as dificuldades. Que poderia fazer, de sua parte, o partido popular, sem maior experiência de govêrno e sem programa definitivo? Torna-se difícil negar, pois, que, ao lado da decomposição das instituições tradicionais, a idéia monárquica surgia como um valor positivo, não obstante a

(8). 一 Op. cit. p. 47.

(9). - ROSTOVTZEFF (Miguel); Historia Social y Económica del Imperio Romano. (Trad. esp.) 2 ed. Madrid, Espasa Calpe, S. A., 1962, v.'1, cap. 1, p. 59 . 
manifesta repulsa dos romanos à realeza tirânica da qual guardavam a lembrança mais amarga. Os arranhões à ordem constitucional republicana tornaram-se inevitáveis diante da fraqueza da oligarquia e do prestígio cada vez mais pronunciado dos generais. Incrustado no seio da própria Constituição, o poder militar passou a significar uma permanente ameaça ao estado. Tais chefes militares colocavam-se em situação duplamente privilegiada sôbre os cônsules e os pretores, bem como sôbre os demais magistrados: emancipavam-se do princípio da colegialidade, pois exerciam suas funções longe da metrópole, o que lhes garantia uma liberdade não conhecida pelos seus colegas, cujas atribuições os prendiam a Roma ou à Itália; e, como representantes exclusivos, exerciam na sua cirçunscrição provincial uma autoridade quase absoluta. Concomitantemente, a vida pública registrava frequientes escândalos eleitorais, a venalidade constituía a nota predominante a anarquia administrativa alcançava sua fase áurea. Na verdade, a Constituição romana do século I não passava, segundo Piganiol, de (10) .

"um amontoado de disparates e de textos que se contradiziam"

Os plebiscitos, criando comandos extraordinários com prazos dilatados, contribuíram para comprometer uma situação já grave em si mesma. O de Gabínio assinalaria o comêço de uma infração, imediatamente tornada norma de conduta geral. O prolongamento do imperium de Pompeu e os desrespeitos posteriores anunciavam que o regime republicano chegava ao seu têrmo.

Roma conheceu então o reinado da eloqüência. Cícero estreava na tribuna política, emprestando seu extraordinário talento verbal à aprovação da lex Manilia (11), que outorgava a Pompeu um poder soberano, sem limitação de tempo. A defesa da rogatio Manilia encerrava um magnificente elogio às glórias de Pompeu, invocava a tradição de Roma, sempre pronta a defender seus aliados, e exaltava a angústia financeira do tesouro público e das sociedades publicanas (12).

A missão do imperator conheceu um término feliz e Pompeu conheceu o auge de sua glória. Durante sua ausência, a situação em Roma permaneceu confusa. A crise econômica gerava descontentamento e a carreira do "nôvo Alexandre", realizada fora da área constitucional, tornou-se uma perigosa sugestão e suscitava imitadores.

(10). - PIGANIOL (André), La Conquête Romaine. Coll. "Peuples et Civilisation", dir. Halphen et Sagnac. Paris, PUF, 1944. p. 380.

(11) . - CfCERO, Pro lege Manilia. XIII, 10, 12, 14, 15, 16, 21, 22, 23.

(12) . - CfCero, Pro lege Manilia. XIII, 5, 6, 7 . 
No plano político, Crasso e César desfechavam golpes contra os optimates. O primeiro tentando inscrever os transpandanos no grupo de cidadãos e César, ao presidir um júri criminal, condenando os sicários da época sulaniana. Golpe de mestre, que aumentou seu prestígio diante do povo.

Entre o imperium de Pompeu no Oriente e seu regresso vitorioso, insere-se o consulado de Cícero. A ascensão do orador à suprema magistratura constituiu-se em quase um triunfo: havia trinta anos que um homo novus não chegava à dignidade consular. Cícero pertencia à classe dos cavaleiros, que, divorciados da vida pública, tiveram de procurar outra atividade. A nobreza maltratava êsses plebeus desconhecidos, a quem a fortuna e os negócios propiciaram riquezas imensas. No programa dêsse moderado, que agora alcançavva o supremo mando, primava o sincero desejo de união entre os nobres e os cavaleiros. E essa seria a sua obra mais aplaudida. Em segundo lugar, a defesa intransigente dos direitos do povo, dentro do limite legal e de acôrdo com o interêsse superior do Estado. Propunha-se, finalmente, o candidato ao mais irrestrito combate aos corruptos, aos subversores e aos poderosos, que confundiam cargos com seus interêsses pessoais e dêles se valiam para explorar os indefesos (13). A vitória de Cícero nas eleições, releva notar, devia-se, exclusivamente, aos seus méritos pessoais. E tanto maior realce alcança sua combatida figura, ao se ter em mente que, enquanto em Roma a carreira política se processava pelas armas, Cícero tentava realizá-la encarnando idéias civilistas (14). A política de Roma defrontava-se, então, com tríplice obstáculo, a bandeira da revisão territorial, conduzida pelos partidários de César: a agitação de nobres descontentes e ambiciosos,

\footnotetext{
(13). - DRUMANN, apolado em Cassius Dio, propalou a crença de que Cícero náo passou de um fraco. O sábio MOMMSEN deu curso às críticas arbitrárias, pretendendo estabelecer, como juizo definitivo, a fraqueza de Cicero. CARCOPINO, mais recentemente, incumbiu-se de proclamar a fragillidade da atuaçăo política do grande orador. (Cf. Les Secrets de la Correspondence de Ciceron. 2 t. Paris, L'Artisan du Livre, 1947). Ergueram-se em defesa de Cícero, além de outros: Emmanuele CIACERI, Ciceroni $e$ i suoi tempi.; Maffio MAFFII. Cicerón y su Drama Politico. (trad. esp.). Buenos Aires, J. Gil, Ed., 1944. Cf. ainda Daniel Valle RIBEIRO. Cicero e a Soluçáo Política da Guerra Civil. Tese de concurso. B. Horizonte, 1962. Contrapondo-se a DRUMANN, que fulminou contia a memória de Cícero a justiça da História, assevera o eminente BOUCHÉ-LECLERCQ: "Justice suspecte d'ailleurs, et dont l'excessive sévérité, aggravée depuis encore par les sarcasmes dédalgneux de $\mathrm{Th}$. Mommsen, a tourné en définitive au profit de l'accusé. On a compris qu'il était inique de comparer sans cesse la marche sinueuse d'une existence ballotté far tant d'événements à un idéal de vertu rectligne qui n'a jamais existé". - BOUCHE-LECLERCQ. Leçons D'Histoire Romaine. République et Empire. 2 ed., Paris, Hachette, 1913. p. 60.

(14). - RIBEIRO (Daniel Valle), Op: cit. p. 108 e 153.
} 
orientada por Catilina; e um movimento provincial, reclamando ampliação de seus direitos políticos, fomentado por ambas as correntes. Os chefes da oposição buscavam conquistar um poder extraordinário para fazer frente a Pompeu quando êste regressasse da Âsia.

Em dezembro de 64 a. C., o tribuno Servílio Rulo pôs em execução o programa revolucionário. Apresentou um projeto de lei agrária, bem elaborado, que prescrevia o loteamento do domínio público (15). Conferia-se sua execução a uma comissão extraordinária de dez pessoas, as quais, durante cinco anos, dispunham de autoridade para adquirir, onde julgassem oportuno, terras cultiváveis para distribuí-las como melhor thes aprouvesse. Esses decênviros tinham ainda a faculdade de anexar ao produto da venda dos territórios dominais as somas dos tributos, prêsas de guerra e saques dos generais, a exceção de Pompeu. As somas arrecadadas não seriam destinadas ao tesouro do Estado, mas aplicadas na obtenção de novos domínios. A repartição das terras visaria aos cidadãos pobres, a começar pela plebe urbana (16).

A rogatio Servilia continhá, como se vê, apreciáveis valores no seu enunciado: afastava de Roma a enorme massa de desocupados, com inegável vantagem para a paz social; estimulava a criação de novas colônias agrícolas; dividia os latifúndios em pequenas propriedades; propiciava uma revisão nas fortunas ilícitas acumuladas pelos generais, forçando-os a restituir a parte subtraída ao erário. No fundo, realmente, acobertava a insídia dos democratas. Se aprovada, a lei submeteria o Estado ao arbítrio de dez indivíduos, escolhidos pelo sufrágio de apenas 17 tribos, como na indicação dos pontífices, lançaria sôbre Roma a população cujas terras viessem a ser vendidas e entregaria, inegàvelmente, aos demagogos uma perigosa e oportuna arma de agitação. Cícero divisou logo na proposição de Rulo a sombra de César e de Crasso, que pretendiam arranhar-lhe a popularidade e reabrir a questão do Egito (17). O cônsul combateu, vigorosamente, a rogatio diante do Senado e da Assembléia Popular, fazendo malograr o intento dos populares. César e Crasso provavam nova derrota. Entrementes, César alçava-se ao cargo de pontifex maximus, o que lhe atribuía a suprema direção do culto oficial e o privilégio da vitaliciedade. Ora,

$$
\begin{aligned}
& \text { "em meio às flutuações da política e à instabilidade dos co- } \\
& \text { mandos anuais - ensina Carcopino - o soberano pontificado cons- }
\end{aligned}
$$

(15) . - CfCERO, De lege agr. I, 2, 4; II, 14, 19, 31, 35, 36.

(16). - CfCERO, De lege agr. I, 3, 4, 5, 7; II, 7, 13 .

(17). - CfCERO, De lege agr. I, 5; II, 9, 16. 
tituía uma autoridade inabalável e perpétua, que o libertava do capricho dos homens" (18).

Compreenderam os conservadores, diante de tantas ameaças, a necessidade de se agruparem em tôrno de Cícero.

Críticas ásperas não têm perdoado essa ligação. Cícero, importa lembrar, não se uniu à nobreza senão depois de vencer sua repugnância à oligarquia senatorial e quando a corrente democrática se ocupava de pertubar a República. Ele não identificava sua conduta com os interêsses do partido conservador. Não pensava nos optimates, mas no Estado e nas instituições, motivo por que lutava por uma reconciliação entre os aristocratas e os cavaleiros. A presença de César e de Crasso nas fileiras dos democratas impeliu-o para o lado do partido oligárquico. $\mathrm{Na}$ realidade, o que pretendiam os democratas era uma posição militar suficientemente forte para contrabalançar os poderes de Pompeu. Arrojavam-se ao poder militar para fugir à ditadura pompeana (19) .

A reta intenção do cônsul, ao colocar-se como guardião dos poderes constituídos, não nos permite partilhar da opinião de Mommsen, quando êste pretende fazer de Cícero um magistrado benevolente e sempre pronto a uma aproximação com qualquer das facções políticas (20). Para um exame desapaixonado, isento e justo da posição de Cícero na vida política de Roma, ou, em outras palavras, para a compreensão do drama ciceroneano, não pode ser desprezado um aspecto de singular importância: êle é um "puro civil" atuando e lutando num momento em que se arma um contexto militar. O instante em que viveu, extremamente turbulento, exigia de seus personagens grande apêgo à violência. Isso explica, em grande parte, suas dúvidas e incertezas, súas fraquezas e desesperos. Por outro lado, Cícero foi um homem de centro, um moderado, e êstes não contentam a ninguém, sobretudo quando as posições se radicalizam.

- O caminho da monarquia parecia mais uma vez aberto quando Pompeu regressou a Roma, em fins de 62. Todos sentiam a debilidade do poder civil diante do imperator onipotente. Mas êsse eterno hesitante dispensou suas tropas, contentando-se com as pompas e o renome que arrastava depois de suas vitórias orientais.

"Il n'y a point chez lui - registra Harmand - cet effort pour remodeler l'Etat, point d'idées créatrices pour le forger d'après un système nouveau" (21).

(18). - BLOCH (Gustave) e CARCOPiNo (Jérôme), Op. Cit. p. 667.

(19). - RIBEIRO (Daniel Valle), Op. cit. p. 114-16.

(20). - MOMMSEN (Teodoro), Historia de Roma. (trad. esp.). Buenos Aires, Joaquim Gil - Ed., 1960. p. 658-9.

(21). - haRMAND, Op. cit., 53. 
Incapaz de firmeza, êle se satisfaz em postular um segundo consulado, mas teve de optar pelo triunfo diante da negativa dos patres. A aristocracia, míope e sem grandeza, retardando a ratificação dos atos de Pompeu no Oriente, acabou lançando-o na corrente democrática. Cícero não soube ou não pôde manobrar o Senado em favor das pretensões do general. Com efeito, o instante era decisivo e a oportunidade excelente para restabelecer uma aliança entre o partido constitucional e êste homem ambicioso de honras. A intransigência de Catão, o Jovem, de inegável valor moral, porém de escassa visão política, também foi responsável pelo desvio de Pompeu.

A situação romana, já acentuadamente confusa e turbulenta, agravou-se com a eleição de César para o consulado, pois sua vitória revelava a existência de um pacto entre êle, Pompeu e Crasso, instituído à margem do Estado e cujo objetivo era a conquista efetiva do poder. Nesse triunvirato poderoso, Crasso oferecia o dinheiro, Pompeu seus veteranos e suas conquistas orientais e César o seu gênio político $\mathrm{e} o$ seu prestígio junto às massas. A aliança, impròpriamente designada como primeiro triunvirato, logo pareceu a Cícero uma união contra o regime. Permaneceu então isolado, supondo que só a ressurreição do Senado poderia restabelecer o equilíbrio perdido. Mas como criar uma República isenta de tantos e tão graves defeitos contando-se apenas com patrícios que sòmente visavam aos privilégios de sua casta? Cícero desejava uma República perfeitamente civil, porém teve de contentar-se em evitar os males flagrantes de um poder militar cada vez mais pronunciado. Sua negativa de entrar na coalisão, caminho que lhe seria fácil e proveitoso, comprova que sua consciência repelia a aproximação com os inimigos da Constituição. César o atraiu. Êle, contudo, soube resistir, fiel aos seus princípios. Não se iludia, entretanto, com a ameaça que pesava sôbre o Estado com o triunfo militar. Efetivamente, o acôrdo entre os três generais só podia esbarrar na oposição da aristocracia, mas esta carecia de fôrças e de homens capazes para reerguer o prestígio do grupo dirigente. $\mathrm{Na}$ área constitucional, despovoada de políticos vigorosos, só se distingüia P. Catão, cuja intervenção, não obstante, expressava mais firmeza e honestidade do que sabedoria e talento (22).

O divórcio entre os aristocratas e os cavaleiros deixara impotente o partido conservador, e, dessa forma, o consulado de César viria marcar uma fase decisiva na marcha para a monarquia. Se diante da decomposição do regime tradicional a monarquia despontava como inevitável, que forma tomaria? Tenderia para um sistema como o idealizado por Péricles, ou se inclinaria para um regime do 
tipo helenístico? Durante os vários decênios que separaram o regime de Sila do que seria instaurado por Otávio, várias concepções se esboçaram. Uma delas, elaborada por Cícero, buscava atender às exigências do estado mediterrâneo.

No pensamento ciceroneano (23), sòmente um conjunto harmonioso de podêres edificaria uma forma mais perfeita de regime, permitindo um Estado acima dos interêsses partidários e dos cidadãos em particular. Esse regime, segundo sua concepção, seria uma síntese acabada dos podêres monárquico, aristocrático e democrático, já qque sua aplicação isolada oferecia graves inconvenientes. Para Cícero, Roma possuía a Constituição que serviria, durante muito tempo, como brilhante modêlo de equilíbrio político. Todavia, o Estado Romano encontrava-se agora ameaçado pela influência perniciosa dos inescrupulosos, que subverteram a ordem jurídica e os valores morais (24). O rompimento do equilíbrio de fôrças reduzira-o ao declínio. E se o Estado corria perigo, só existia uma possibilidade de recuperação: confiá-lo a um protetor, sob cuja direção as instituições recobrariam o antigo vigor. Dêsse regente, que recebe de Cícero diferentes designações - rector patriae, gubernator, moderator reipublicae - (25), exigiam-se qualidades indispensáveis de prudência, conhecimento de leis, justiça, eloquiência, sabedoria e firmeza. Assim como o pilôto procura um feliz êxito para sua rota, o médico cuida da saúde de seus enfermos e o general persegue a vitória, o homem de estado deve ter em vista a felicidade dos cidadãos. Mas há de apoiar-se em recursos seguros para um integral cumprimento de sua tarefa (26).

Em quem teria pensado Cícero, ao esboçar êsse primus inter pares? A questão sugere várias interpretações.

\footnotetext{
"Sem dúvida, em vários, sucessivamente - responde Harmand em determinados momentos em Pompeu, - nêle mesmo, uma vez que era considerado optimus civis; - em uma barganha entre Pompeu e êle, se é verdade que haja oferecido a Pompeu uma colaboração e que êste a tenha rejeitado" (27).
}

Homo inclina-se por Pompeu, asseverando que êste seguia fiel ao seu sonho de Principado e que deteve, a partir de 54, ainda que em estado embrionário, os podêres de princeps (28). Maffii, por seu turno, não crê que o De Republica seja uma obra à clef. Cícero pretendeu apenas, afirma,

(23). - CICERO, De Rep. I, 35, 45.

(24). - CICERO, De Rep. V, fragmento 9.

(25) . - CICERO, De Rep. II, 29; e fragmentos do livro V.

(26). - CfCERO, De Rep. V, 6.

(27). - HARMAND, Op, cit. p. 52. 
"atribuir ao rector por êle imaginado as qualidades de Cipião Emiliano, o homem do passado que, nêle, suscitava a maior admiração, e do qual desejava, sem esperá-lo, um igual para a salvação de Roma" (29).

\section{Para Cousin,}

"o advento de Augusto é o do mais forte, do melhor, uma prostasia, com diriam os gregos, que fazia do princeps um "primeiro pela autoridade", como sonhara Cícero e como o dizia o próprio Augusto" (30).

Discute-se, igualmente, se o princeps da versão de Augusto corresponde ao do modêlo ciceroneano. Sem dúvida, Augusto valeu-se do vocabulário de Cícero, e, não obstante lhe emprestando um outro sentido, pôs em prática a linha geral de sua doutrina. Sem possuir o talento criador de César, Otávio revelou extraordinária prudência e habilidade, sabendo conferir à nova ordem a aparência antiga, vinculando as inovações à tradição. Segundo a penetrante observação de Carcopino, êle foi imperator fora de Roma e princeps dentro dela, em vez de se intitular, como César, ditador entre os romanos e rei fora (31). Isso, a nosso ver, atenuava os males e os exageros da irremediável monarquia militar e convergia para a fórmula de Cícero: equilíbrio entre o poder pessoal e a soberania do Senado como solução para o problema da sobrevivência da liberdade na República. Só que no pensamento de Augusto encobriam-se a astúcia e segundas intenções.

\footnotetext{
(28) . - HOMO, Op. cit., 221.

(29) . - MAFFII, Op. cit., 243.

(30). - BLOCH (Raymond) e COUSIN (Jean), Roma e seu destino (tra. port.). Lisboa, Ed. Cosmos, 1964, p. 244.

(31). - CARCOPINO (Jéróme), César. In "La République Romaine de 133 a 44 avant J. C.". 4 ed., Paris, PUF, 1950 (Histoire Romaine, t. II) . p. 1047-8.
} 